\title{
Effects of hydraulic retention time, temperature, and MLSS concentration on the effluent quality of a membrane bioreactor
}

\author{
J. M. Poyatos ${ }^{1,2}$, M. Molina-Muñoz ${ }^{2}$, J. González-López ${ }^{2}$ \\ \& E. Hontoria ${ }^{1,2}$ \\ ${ }^{1}$ Department of Civil Engineering, University of Granada, Granada, \\ Spain \\ ${ }^{2}$ Institute of Water Research, University of Granada, Granada, Spain
}

\begin{abstract}
The performance of a bench-scale submerged membrane bioreactor (MBR) equipped with ultrafiltration membranes (ZENON®) was investigated. The running of the plant consisted of 10 min cycles: a cycle included 9 min $45 \mathrm{sec}$ of filtration and a $15 \mathrm{sec}$ back flush cycle. Three different hydraulic retention times (HRT) were utilized $(8.05,11.71$ and $15.27 \mathrm{~h}$ ) at several different concentrations of MLSS. The pilot plant was located at the wastewater treatment plant of the city of Granada (Puente de los Vados, Granada, Spain).

The results showed that the MBR systems were highly efficient at removing organic matter (COD and BOD5), suspended solids, turbidity, colour and microbial indicators (E. coli and coliphages) in the urban wastewater. Statistical analysis of the data indicated that the hydraulic retention time was the parameter which most affected the elimination of BOD5, as reflected by the significant statistical differences. However, E. coli and coliphages were practically removed in the MBR system independently of the HRT values, temperature and MLSS concentrations utilized in the experiment. Likewise, coliphages were virtually eliminated, and no relationship was found between this elimination and HRT influence, temperature, or MLSS concentration.
\end{abstract}

Keywords: membrane bioreactor, wastewater reuse, ultrafiltration, water quality. 


\section{Introduction}

Although conventional activated sludge processes (CASPs) have established their efficiency in removing contamination from sewage water, technical developments require new technologies better adapted to the elimination of contaminants in order to attain a quality of effluent acceptable for direct reuse of the wastewater. The adaptability of membrane bioreactor (MBR) systems means they can adjust to previously established activated sludge plants, increasing the volume loading rate of the influent and/or the load that current treatment plants accommodate [1]. This could help growing municipalities to resolve the problem of the intake capacity of wastewater treatment plants becoming too small for the estimated population growth. Additionally, the space required for new plants applying the MBR systems would be much smaller than for an activated sludge plant. Moreover, this wastewater-treatment technology produces a permeate which is suitable for direct reuse.

Ever since research on MBR technology began over 30 years ago [2], ultrafiltration has been considered as a possible alternative to sedimentation in the activated-sludge process, as first described by Smith et al. [3]. Since then the advance of the MBR technology has been notable, and today large companies commercialize membrane bioreactors with sheet membranes [4].

The possibility of adapting existing plants to MBR technology offers the advantage of producing effluent of sufficient quality for direct reuse [5], while the CASP approach requires tertiary filtration to produce water that can be directly reused [1].

The reuse of treated wastewater is limited owing to the prevailing presence of pathogenic microorganisms. That is to say, even after physical and biological water treatment processes, pathogens - primarily of faecal origin - survive unharmed. Nevertheless, one of the most efficient pathogen-removal processes is the use of membrane filtration. In this respect, MBRs are capable of reducing the number of pathogens since the incorporated ultrafiltration membrane has the capacity to retain bacteria and some types of viruses.

Several studies have proved the efficiency of MBR systems equipped with microfiltration membranes in the removal of faecal coliforms [6]. Similarly, with regard to virus removal, studies have demonstrated an efficiency rate of $98 \%$ by microfiltration MBR systems [7]. These systems have also been shown to be effective at decreasing viruses detected in the biofilm formed on the membrane [8].

The objective of the present study was to assess the effects of several working parameters (HRT, Temperature and MLSS concentration) on the quality of the effluent produced in an MBR plant equipped with ultrafiltration membranes.

\section{Materials and methods}

\subsection{Membrane and bioreactor}

The membrane $\left(\right.$ Zenon $^{\circledR}$ ) was composed of a polymer of polvinyl-difluoride (PVDF) containing an average pore size of $0.04 \mu \mathrm{m}$. The membrane was 
neutrally charged and hydrophilic. To prevent fouling, membranes were periodically backwashed. The membrane configuration was from the outside to the inside of the hollow fibre: the filtrate passed to the interior of the fibre, leaving retained material on the outside. In this way, an effluent with higher suspended-solid (SS) concentrations could be obtained.

The main components of the system (Figure 1) were: the 2241 bioreactor; a control panel; a pressure pump; an air pump to generate a tangential aeration current to the fibre in the membrane in order to avoid fouling, and a 251 backwash tank. The filtrate and backwash processes were controlled directly from the control panel. The system also contained an air compressor to supply the air required to maintain oxic conditions of the biological aerobic processes.

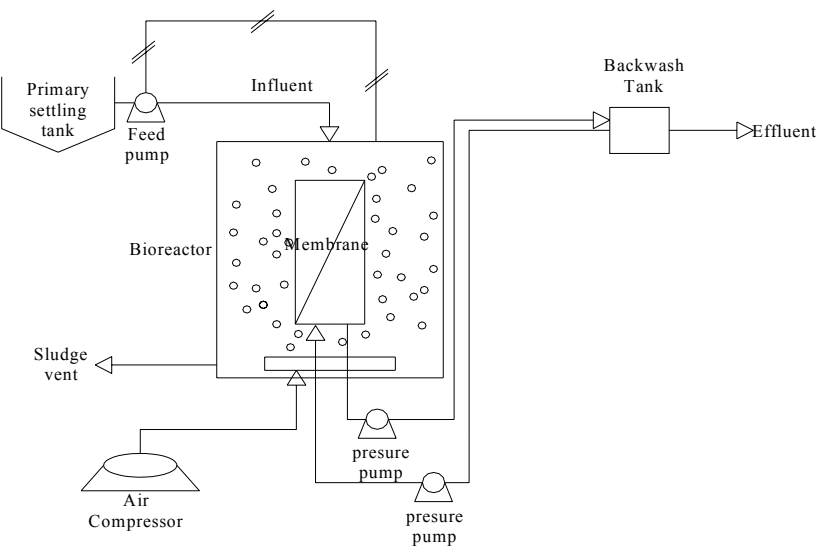

Figure 1: Diagram of the MBR pilot-scale plant used in the study.

The pilot plant was located at the wastewater treatment plant of the city of Granada (Puente de los Vados, Granada, Spain). The influent used in the pilot plant came from the primary settling tank of the wastewater-treatment plant; feed/input was controlled by a pressure pump for each membrane, located at the outlet. The system was equipped with a level control to ensure that the membranes were always covered with water, preventing them from drying or ripping. Additionally, a level indicator was installed to control the pressure pump.

\subsection{Experimental procedure}

Once the membranes were submerged, the aspiration of the pressure pump forced the liquid in the bioreactor to pass through the ultrafiltration membrane, leaving the retained solids in the bioreactor and thereby gradually increasing the MLSS concentration. When the desired concentration was achieved, the corresponding sludge vents were opened to maintain the specific conditions in 
the reactor. The membranes were continuously aerated with tangential air currents $\left(3.66 \mathrm{~m}^{3} \mathrm{~h}^{-1} \mathrm{~m}^{-2}\right)$ to prevent any organic or inorganic solids from settling on their surface. A compressor provided the adequate aerobic conditions for the process. Dissolved oxygen (DO) was monitored and controlled using an oxygen electrode (Crisol OXI 320). The pressure pump inverted the flow regularly and sent the treated water inside the backwash tank towards membrane. In this way, aggregates and particles were removed from the surface of the membrane. Running of the plant consisted of 10-min cycles: one cycle included 9 min 45 sec of filtration and a $15 \mathrm{sec}$ backwash cycle.

\subsection{Sampling and analytical determinations}

\subsubsection{Physical and chemical determinations}

$\mathrm{BOD}_{5}, \mathrm{COD}$, turbidity and solids in suspension (SS) were determined according to the APHA method [9]. The colour of the water samples was established by measuring filtered samples $(0.45 \mu \mathrm{m}$ membrane pore size) at three different wavelengths: 436, 525 and $620 \mathrm{~nm}$, in accordance with Spanish regulations [10].

\subsubsection{Microbial determination}

Escherichia coli and phages of E. coli were selected as bacterial and viral indicators of faecal contamination (IFCs). For the quantitative analysis of faecal coliforms (E. coli), the membrane-filtration procedure was used, following Spanish regulations [11]. $10 \mathrm{ml}$ water samples were filtered through a $0.45 \mu \mathrm{m}$ membrane filter (Millipore) and placed in Petri dishes containing TBA medium. The Petri dishes were incubated at $37^{\circ} \mathrm{C}$ for $4 \mathrm{~h}$ and then incubated aerobically at $44.5^{\circ} \mathrm{C}$ for $20 \mathrm{~h}$. After this incubation time one drop of Indol reagent was added to the colonies. Colonies with red colour were considered to be $E$. coli. The colony count for each site was calculated from the arithmetic mean of counts from three filter membranes (replicates of the same volume).

The presence of coliphages in the influent, bioreactor and permeate was investigated by means of the double-layer method [12], using E. coli ATCC 13706 as the host strain. Water samples $(10 \mathrm{ml})$ were filtered through $0.45 \mu \mathrm{m}$ membrane filters (Millipore) to remove bacterial cells. The resulting filtrates were tested for phages. Erlenmeyer flasks containing $25 \mathrm{ml}$ of TSA were steamed to liquefy the agar and adjusted to $44{ }^{\circ} \mathrm{C}$. The filtered-water sample to be tested was supplemented with solutions of $1 \mathrm{ml}$ of $\mathrm{CaCl}_{2}$ plus $1 \mathrm{ml}$ of $\mathrm{MgCl}_{2}$, and $25 \mathrm{ml}$ of the water was poured into each of four sterile Erlenmeyer flasks. Next, $1 \mathrm{ml}$ of the culture which had been incubated overnight was added to each flask. The water sample and host culture of the indicator strain were sampled and then maintained at $44{ }^{\circ} \mathrm{C}$ for $3 \mathrm{~min}$, after which they were added to the flasks containing the TSA. The TSA was then poured in equal volumes into Petri dishes containing TSA as bottom layer, and allowed to solidify. Plates were incubated overnight at $37^{\circ} \mathrm{C}$ and lytic plaques were counted.

\subsubsection{Statistical analysis}

Data obtained throughout this study were analysed using the SPSS 13.0 for Windows computer-assisted statistics program. The Least Significant 
Differences test (LSD-test) was used to measure differences between the selected strains for the various parameters analysed, both in the support material and in the effluent. The analysis of variance (ANOVA) was used to assess the homogeneity of variance, with a significance level of $5 \%(p<0.05)$.

\section{Results and discussion}

Three different HRT $(8.05,11.71$ and $15.27 \mathrm{~h})$ were utilized in the experiments. Under these working conditions, the temperature and the concentration of MLSS were modified in order to study the effect of these parameters on the elimination of COD, BOD and faecal indicators. Table 1 shows the different pilot plant working conditions.

Table 1: $\quad$ Pilot plant working conditions utilized in the present experiments.

\begin{tabular}{|c|c|c|c|c|c|c|c|}
\hline \multirow{2}{*}{$\frac{\text { Experiment }}{1}$} & \multirow[t]{2}{*}{$\begin{array}{c}\text { HRT, } \\
\text { h }\end{array}$} & \multicolumn{3}{|c|}{$\begin{array}{c}\text { MLSS }^{\mathbf{a}} \\
\mathrm{mg} / \mathbf{l}\end{array}$} & \multicolumn{3}{|c|}{$\begin{array}{l}\mathrm{T}^{\mathrm{a} \mathbf{a}} \\
{ }^{\mathrm{o}} \mathrm{C}\end{array}$} \\
\hline & & 3070 & \pm & 442 & 14.8 & \pm & 2.3 \\
\hline 2 & \multirow{4}{*}{11.71} & 4315 & \pm & 653 & 22.5 & \pm & 2.0 \\
\hline 3 & & 5048 & \pm & 339 & 23.9 & \pm & 1.1 \\
\hline 4 & & 6204 & \pm & 424 & 23.2 & \pm & 1.7 \\
\hline 5 & & 6970 & \pm & 702 & 16.4 & \pm & 2.8 \\
\hline 6 & \multirow{4}{*}{8.05} & 7448 & \pm & 956 & 10.9 & \pm & 2.9 \\
\hline 7 & & 14292 & \pm & 1137 & 9.2 & \pm & 1.6 \\
\hline 8 & & 12264 & \pm & 1404 & 18.9 & \pm & 2.6 \\
\hline 9 & & 9858 & \pm & 725 & 8.3 & \pm & 2.5 \\
\hline 10 & \multirow{2}{*}{15.27} & 7023 & \pm & 774 & 23.4 & \pm & 1.5 \\
\hline 11 & & 10371 & \pm & 973 & 16.4 & \pm & 1.7 \\
\hline
\end{tabular}

${ }^{\mathrm{a}}$ Values are means of 20 replications \pm standard deviation.

Table 2 shows $\mathrm{BOD}_{5}$ and $\mathrm{COD}$ values in the influent and permeate in each experimental condition. Samples for these determinations were taken in the MBR system after 30 days from the start-up of the process, to ensure the stability of operational conditions in the pilot plant.

The results show that an increase in the HRT in the MBR system significantly decreases the $\mathrm{BOD}_{5}$ values in the permeate, while process variables such as temperature and MLSS slightly improved the elimination of organic matter, although no significant differences were detected. Our data suggest that the microbial populations involved in the biodegradation of organic matter become more efficient after longer periods of HRT, probably as a consequence of an adaptation of the microbial biodiversity to the plant working conditions. In this context, previous studies have reported the significant influence of the HRT on the biodiversity in MBR systems working under different MLSS concentrations [13].

$E$. coli and coliphages were not detected in the permeate in any of the working conditions utilized in the present experiments. Clearly, the ultrafiltration 
membrane was able to remove bacteria and viruses present in the influent and consequently the permeate was free of these microbial indicators. Similar results

Table 2: $\quad \mathrm{BOD}_{5}$ and COD average values in MBR influent and effluent with the corresponding elimination performance obtained during the last week of each MLSS concentration interval studied.

\begin{tabular}{|c|c|c|c|c|c|c|c|c|c|c|c|c|c|c|c|c|c|}
\hline \multirow{2}{*}{$\frac{\text { Exp.* }}{1}$} & \multicolumn{3}{|c|}{$\begin{array}{c}\text { BOD5e, } \\
\mathrm{mg} / 1\end{array}$} & \multicolumn{3}{|c|}{$\begin{array}{c}\text { BOD5s, } \\
\mathrm{mg} / 1\end{array}$} & \multicolumn{2}{|c|}{$\begin{array}{c}\% \text { elimination } \\
\mathrm{BOD}_{5}\end{array}$} & \multicolumn{3}{|c|}{$\begin{array}{c}\text { CODe, } \\
\mathrm{mg} / \mathrm{l}\end{array}$} & \multicolumn{3}{|c|}{$\begin{array}{c}\text { CODs, } \\
\mathrm{mg} / 1\end{array}$} & \multicolumn{3}{|c|}{$\begin{array}{c}\% \text { elimination } \\
\mathrm{COD}\end{array}$} \\
\hline & 370 & \pm & 55 & 23 & + & 12 & 94 & $\pm 3.7 \mathrm{ab}$ & 453 & \pm & 69 & 55 & \pm & 30 & 87 & \pm & $8 \mathrm{c}$ \\
\hline 2 & 290 & 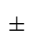 & 53 & 8.6 & + & 5.3 & 97 & $\pm 1.5 \mathrm{ab}$ & 467 & \pm & 89 & 38 & \pm & 26 & 92 & \pm & $5.8 \mathrm{c}$ \\
\hline 3 & 313 & \pm & 54 & 6.5 & \pm & 2.6 & 98 & $\pm 0.8 \mathrm{ab}$ & 398 & \pm & 47 & 22 & \pm & 9 & 94 & \pm & $2.4 \mathrm{c}$ \\
\hline 4 & 318 & \pm & 59 & 9.4 & \pm & 3.2 & 97 & $\pm 0.8 \mathrm{ab}$ & 430 & \pm & 110 & 36 & \pm & 35 & 92 & \pm & $5.5 \mathrm{c}$ \\
\hline 5 & 413 & \pm & 49 & 8.7 & \pm & 5.8 & 98 & $\pm 1.4 \mathrm{ab}$ & 342 & \pm & 177 & 39 & \pm & 45 & 91 & \pm & $7.3 \mathrm{c}$ \\
\hline 6 & 337 & \pm & 23 & 25 & \pm & 22 & 93 & $\pm 6.1 \mathrm{a}$ & 444 & \pm & 34 & 52 & \pm & 18 & 88 & \pm & $3.6 \mathrm{c}$ \\
\hline 7 & 393 & \pm & 114 & 7.8 & $I$ & 4.9 & 98 & $\pm 1 \mathrm{a}$ & 635 & \pm & 77 & 42 & \pm & 21 & 93 & \pm & $3.2 \mathrm{c}$ \\
\hline 8 & 396 & \pm & 99 & 28 & \pm & 15 & 92 & $\pm 6 \mathrm{a}$ & 517 & \pm & 13 & 83 & \pm & 15 & 84 & \pm & $3.2 \mathrm{c}$ \\
\hline 9 & 427 & \pm & 104 & 20 & \pm & 3.3 & 95 & $\pm 0.4 \mathrm{a}$ & 541 & \pm & 96 & 41 & \pm & 13 & 92 & \pm & $2.3 \mathrm{c}$ \\
\hline 10 & 251 & \pm & 76 & 5.2 & \pm & 1.8 & 98 & $\pm 1.3 \mathrm{~b}$ & 344 & \pm & 84 & 30 & \pm & 14 & 91 & & $4.3 \mathrm{c}$ \\
\hline 11 & 413 & \pm & 66 & 4.2 & \pm & 2.9 & 99 & $\pm 0.7 \mathrm{~b}$ & 482 & \pm & 84 & 31 & \pm & 11 & 93 & \pm & $3.7 \mathrm{c}$ \\
\hline
\end{tabular}

*See Table 1 .

BOD5i.- BOD in the influent; CODi.-COD in the influent; BOD5e.- BOD in the effluent; CODe.-COD in the effluent

Experiments with the same letter are not significantly different, according to the LSD-test. The analysis of variance (ANOVA) was used to assess the homogeneity of variance with a significance level of $5 \%(p<0.05)$.

have been reported by previous studies [14-16]. According to Ueda and Horan [17], this high level of performance in microbial elimination is due to three different mechanisms. The first mechanism is physical, namely the pore size of the membrane; the second is chemical, namely the adsorption of the microbial indicators by the biofilm formed in the membrane; and the third is a biological component, as a result of the predation of bacteria by other microorganisms.

Finally, no turbidity was detected in the permeate obtained from the MBR systems under the different working conditions (HRT, temperature and MLSS concentration). However, in all the experiments a residual colour was detected in the permeate, showing that the ultrafiltration membrane cannot completely remove the colour of the treated urban wastewater. 


\section{Conclusions}

Under real working conditions, the effects of HRT, MLSS and Temperature were studied in an MBR system equipped with ultrafiltration membranes. The data obtained in our experiments suggest the following conclusions:

1) An increase in HRT significantly decreases the $\mathrm{BOD}_{5}$ values detected in the permeates. However, the biodegradation of organic matter was not significantly affected by Temperature and MLSS concentrations.

2) Microbial indicators such as E. coli and coliphages were eliminated by the ultrafiltration membrane under all the experiment conditions assayed. However, a small fraction of colour was detected in the permeate.

3) Turbidity was not detected in the permeate produced by the MBR systems under different HRT, Temperature and MLSS concentrations.

\section{References}

[1] Côté, P.; Masini, M. and Mourato, D. (2004). Comparison of membrane options for water reuse and reclamation. Desalination, 167 1-11.

[2] Stephenson, T.; Judd, S; Jefferson B. and Brindle K. (2002). Membrane bioreactor for wastewater treatment. IWAI Publishing, Cornwall, U.K.

[3] Smith, C.V.; Gregorio, D.O. and Talcott, R.M. (1969) The use of ultrafiltration membranes for activated sludge separation. Proc 24th Ind. Waste Conf., Purdue University, Ann Arbor, USA. 1300-1310.

[4] Judd, S. (2006). The MBR book: Principles and applications of membrane bioreactors in water and wastewater treatment. Elsevier, Amsterdam, Holland.

[5] Yang, W.; Cicek, N. and Ilg, J. (2006). State-of-art of membrane bioreactors: Worldwide research and commercial applications in North America. Journal of Membrane Science, 270 201-21.

[6] Melin, T.; Jefferson, B.; Bixio, D.; Thoeye, C.; De Wilde, W.; De Koning, J.; van der Graaf, J. and Wintgens, T. (2006). Membrane bioreactor technology for wastewater treatment and reuse. Desalination, 187 271-282.

[7] Wen, X.; Ding, H.; Huang, X. and Liu, R. (2004). Treatment of hospital wastewater using a submerged membrane bioreactor. Process Biochemistry, 39 1427-1431.

[8] Chiemchaisri, C.; Wong Y.K.; Urase T. and Yamamoto K. (1992). Organic stabilization and nitrogen removal in membrane separation bioreactor for domestic wastewater treatment. Water Science and Technology, 25(10) 231-240.

[9] APHA, AWWA, WEF (1992). Standard Methods for the examination of water and wastewater, 18th ed., American Public Health Association, Washington, DC., USA.

[10] UNE-EN ISO 7887 (1994). Calidad del Agua. Examen y determinación del color. 
[11] UNE-EN ISO 9308-01 (2001). Calidad del Agua. Detección y recuento de Escherichia coli y de bacterias coliformes.

[12] Adams, M. H. (1959). Bacteriophages. Interscience Publishers, N.Y., USA. 443-451.

[13] Molina-Muñoz, M.; Poyatos, J.M.; Vílchez, R.; Hontoria, E.; Rodelas, B. and González-López, J. Effect of the concentration of suspended solids on the enzymatic activities and biodiversity of a submerged membrane bioreactor for aerobic treatment of domestic wastewater. Applied Microbiology and Biotechnology, 73 (6) 1441-1451.

[14] Till, S.W.; Judd, S.J. and Mcloughlin, B. (1998). Reduction of faecal coliform bacteria in sewage effluent using a microporous polymeric membrane, Wat. Res., 32 1417-1422.

[15] Gander, M.; Jefferson, B. and Judd, S. (2000). Aerobic MBRs for domestic wastewater treatment: a review with cost considerations. Separation and Purification Technology, 18 119-130.

[16] Arrojo, B.; Mosquetera-Corra, A.; Garrido, J.M.; Méndez, R.; Ficara, E. and Malpei, F. A. (2005) Membrane coupled to a sequencing bath reactor for water reuse and removal of coliform bacteria. Desalination, 179 109116.

[17] Ueda, T. and Horan, N.J. (2000). Fate of indigenous bacteriophage in a membrane bioreactor. Wat. Res., 34 (7) 2151-2159. 